\title{
CORRESPONDENCIAS ENTRE AMIGOS PERNAMBUCANOS DA PRIMEIRA METADE DO SÉCULO XX: TRADIÇÃO DISCURSIVA E ENSINO-
}

CORRESPONDENCE BETWEEN PERNAMBUCAN FRIENDS OF THE FIRST HALF OF THE TWENTIETH CENTURY:DISCURSIVE TRADITIONANDTEACHING

\author{
Aldeir Gomes da Silva (UFPE) ${ }^{1}$ \\ Valéria Severina Gomes (UFRPE) ${ }^{2}$
}

\section{RESUMO}

Neste trabalho, analisamos oito cartas de amigos, trocadas por missivistas pernambucanos, em diferentes condições de produção, na primeira metade do século XX. Temos por objetivo identificar os elementos constitutivos que especificam o subgênero carta de amigo; verificar os modos de dizer que se configuram como Tradição Discursiva; por fim, refletir sobre a importância desse conteúdo para os estudos linguísticos em sala de aula, através de atividades que envolvam as propostas dos PCNs: o trabalho com gêneros textuais e a análise linguística (AL). Para tanto, partimos das abordagens de Koch (1997), Oesterreicher (1997, 2006), Kabatek (2003, 2006), Souza (2012), Longhin (2014), Lopes e Gomes (2016), Marcuschi (2011) e Bezerra \& Reinaldo (2013). Os resultados da investigação evidenciam a relação de proximidade entre os interlocutores manifesta por meio dos recursos linguístico-discursivos utilizados; os modos de dizer tradicionais na composição das cartas de amigo; e as possibilidades de transposição dos dados analisados para o ensino.

PALAVRAS-CHAVE: carta de amigo; tradição discursiva; ensino.

1 Mestrando em Linguística da Universidade Federal de Pernambuco. Email: gomes.aldeir@ yahoo.com.br

2 Professora Doutora do Curso de Letras da Universidade Federal Rural de Pernambuco. 


\section{ABSTRACT}

In this work, we analyze eight friend letters, exchanged by writers from Pernambuco, in different conditions, at the first half of the twentieth century. We aim to identify the constitutive elements which specify the subgenre friend letter; to verify the ways of saying which set as Discursive Tradition; ultimately, to reflect on the importance of this content for linguistic studies in the classroom, through activities involving the PCNs' proposals: the work with textual genres and linguistic analysis. For this purpose, we start from the approaches of Koch (1997), Oesterreicher (1997, 2006), Kabatek (2003, 2006), Souza (2012), Longhin (2014), Lopes and Gomes (2016), Marcuschi (2011) and Bezerra \& Reinaldo (2013). The results of the research show the relationship of proximity between the interlocutors manifested through linguistic-discursive resources used; the traditional ways of saying in the composition of the friend letters; and the possibilities of transposing the data analyzed into education.

KEYWORDS: friend letters; discursive tradition; teaching.

\section{CONSIDERAÇÕES INICIAIS}

A carta, hoje, não possui mais a representatividade comunicativa que possuía no passado, devido à substituição por formas de comunicação mais rápidas, como o e-mail por exemplo. Apesar disso, ela é considerada um dos gêneros fundamentais às investigações linguísticas, sobretudo na perspectiva histórica da língua e do texto, uma vez que guarda as marcas das condições de produção de diferentes sincronias passadas. Partimos da concepção de que o fato de surgirem novos meios de comunicação não impede que levemos os alunos a conhecerem a dinamicidade que envolve a historicidade da língua e dos textos até chegarmos aos usos atuais.

Ao longo da história, diversas relações têm sido estabelecidas através da carta e diversas finalidades são a ela atribuídas: a carta pode assumir o papel de um tratado de ciência (as cartas de Freud), de um relato históricogeográfico (a Carta de Pero Vaz de Caminha), de uma obra literária (as Cartas Portuguesas de Mariana Alcoforado), de uma solicitação de emprego ou um pedido de demissão etc. A própria Constituição Brasileira 
é uma carta (a Carta Magna). Por possuir várias naturezas, vertentes e

: finalidades, a carta pode se configurar como um hipergênero, uma vez que o rótulo "carta” adjetivado nomeia diferentes gêneros que ganharam autonomia (carta pessoal, carta administrativa, carta comercial etc.). Ligados por elementos comuns (MAINGUENEAU, 2006), que unem diferentes características e englobam uma variedade de gêneros afins (RAMOS, 2009), os gêneros apresentam alguma afinidade em virtude da raiz comum e alguma especificidade em virtude das particularidades de cada universo discursivo (SCHLIEBEN-LANGE, 1983) em que circula.

Os estudos acerca da carta (ou dos gêneros epistolares) são antigos, com séculos de investigações e questionamentos (BELTRÁN ALMERÍA, 1996). Concebida como gênero mãe, a carta, no universo discursivo do jornalismo, foi o ponto de partida para as cartas de leitor e as cartas do redator (o editorial), pois, de acordo com Rizzini (1968), as cartas ocupavam o lugar do jornal. No universo discursivo da literatura, a missiva também pode, em alguns casos, ser considerada no limite entre os gêneros literários e cotidianos. A diferença entre uma carta pessoal e uma carta literária, por vezes, é muito tênue. De acordo com os estudos de Guillén (1991), isso se deve à aproximação retórica da carta. De tal maneira, a carta é um gênero que perpassa diferentes universos discursivos, a exemplo da carta no domínio pessoal (cartas de família, de amor, de amigo), no domínio jornalístico (carta do leitor, carta do redator) e no domínio comercial (carta de referência, memorando).

Neste artigo, vamos nos deter à carta pessoal, mais especificamente ao subgênero carta de amigo, uma forma de comunicação influenciada por características informais e espontâneas, por isso, muito apreciada nos estudos linguísticos para a composição de um corpus histórico (COSTA, 2012). As cartas pessoais são essencialmente marcadas pela espontaneidade, proximidade comunicativa e por diferentes níveis de intimidade entre remetente e destinatário (SOUZA, 2012). Novaes (2006, p. 5) encara este gênero como uma forma de comunicação essencialmente pessoal, uma correspondência que efetiva um contato privado e, quase sempre, constante entre familiares e amigos íntimos, pessoas que mantêm um relacionamento estreito. 
Nascimento e Espíndola (2008, p. 5) afirmam que a importância do interlocutor, marcado textualmente através de um vocativo, fica evidente quando, por meio desse contato, é possível pressupor a qual gênero uma carta pertence: pessoal (Meu caro amigo), do redator (Meu caro leitor), comercial (Prezado cliente), etc. Cada tipo de carta desses tem no vocativo uma forma tradicional de dizer, que é recorrente na tradição epistolar. No tocante a um trabalho de Análise Linguísticas em sala de aula, levar os alunos a perceberem essas mudanças na forma de tratamento é conduzilos à percepção das condições de produção de produção subjacentes a cada gênero. A essência das cartas está pautada na relação existente entre o remetente e o destinatário, com mais ou menos proximidade, mais ou menos intimidade, mais ou menos informalidade, mais ou menos simetria na relação interpessoal. A respeito dos distintos agrupamentos da carta pessoal, Costa (2012, p. 145) assevera que:

O rótulo "carta pessoal” engloba, na verdade, uma série de realizações com propósitos comunicativos muito diversos, desde o desejo de expressar amizade, o falar sobre religião, o de fazer fofoca sobre a vida alheia, o de dar notícias sobre a família até o de declarar amor de forma íntima.

Sendo assim, a relação entre os interlocutores de uma carta pessoal (pai e filho; filha e mãe; marido e esposa; amigos etc.) implicará no conteúdo temático das missivas, tornando-se um dos fatores determinantes para que se perceba que há finalidades comunicativas específicas e também elementos linguístico-discursivos específicos em uma determinada carta que não se encontrará em outra, mesmo dentro de um mesmo agrupamento rotulado como "carta pessoal”. Com base nos estudos de Silva (2002), que analisa o funcionamento sociocomunicativo das cartas pessoais, e de Souza (2012), que propõe subcategorias ao gênero, temos por objetivos identificar os elementos constitutivos que especificam o subgênero carta de amigo; verificar os modos de dizer que se configuram como Tradição Discursiva; por fim, refletir sobre a importância desse conteúdo para os estudos linguísticos em sala de aula, através de atividades que envolvam as propostas dos PCNs: o trabalho com gêneros textuais e a análise linguística (AL). 
O corpus para a análise é constituído por oito cartas pessoais, de cinco escreventes pernambucanos, produzidas no, ou destinadas ao estado de Pernambuco na primeira metade do século XX. As correspondências inserem-se em um dos três subgêneros propostos por Souza (2012, p. 114): a carta de amigo. As missivas analisadas foram coletadas por Gomes (2014) e fazem parte do projeto Formas tratamentais em cartas pessoais pernambucanas dos séculos XIX e XX: uma interface entre tradição discursiva e sociolinguística bistória. O material coletado foi transcrito segundo os parâmetros sugeridos por Guedes e Berlink (2000). A discussão dos dados obtidos nesta análise qualitativa está fundamentada na sociolinguística histórica com base nos aspectos internos e externos, a exemplo do perfil social dos informantes (CONDE SILVESTRE, 2007).

Sabendo que o ensino de gêneros textuais é recomendado pelos Parâmetros Curriculares Nacionais, é importante salientar a importância do gênero carta pessoal para o ensino de escrita, uma vez que "nunca se escreveu tanto quanto na atualidade” (SANTOS; SILVA, 2014, p.3). Boa parte das produções escritas contemporâneas, em blogs e redes sociais, principalmente, contêm elementos que são oriundos da carta pessoal. Tal fato reforça a constatação de Pessoa (2002, p. 197), que salienta a importância do estudo da "evolução desse gênero textual, a sua função em diferentes épocas e seu papel no desenvolvimento de outros gêneros”. De tal forma, com base nos estudos de Silva (2002), consideraremos relevante refletir sobre a análise da carta, identificando como os traços de interação nos textos podem ser inseridos nos conteúdos de ensino de língua, seja pelo viés diacrônico ou sincrônico.

Os pontos aqui discutidos têm início com a análise dos traços de mudança e permanência dos elementos composicionais dos subgêneros da carta pessoal, considerando a natureza do gênero e o conceito de Tradição Discursiva. Feito isso, buscamos identificar os traços linguísticodiscursivos presentes nas correspondências, considerando o perfil dos escreventes e as relações estabelecidas entre eles. Prosseguimos a discussão com a abordagem e a verificação da existência de traços linguísticodiscursivos que caracterizam as cartas de amigo. Em seguida, propomos uma reflexão acerca da pertinência da transposição desses conteúdos para a sala de aula. Por fim, apresentamos as considerações finais e as referências bibliográficas utilizadas. 


\section{As tradições discursivas e os gêneros}

O conceito de Tradição Discursiva tem se mostrado bastante proveitoso para as análises que enveredam pelo viés da historicidade da língua e dos textos. Desenvolveu-se a partir dos estudos de Coseriu, que propôs três níveis de atividade linguística, dos quais, o nível histórico corresponde aos estudos da historicidade da língua. Peter Koch (1997) sugere a duplicação do nível histórico do modelo de Coseriu, situando, de um lado, as línguas históricas e, de outro lado, as tradições de textos ou tradições discursivas. Dessa forma, Koch considera a historicidade da língua e a historicidade do texto. De acordo com Longhin (2014), as tradições discursivas são modelos textuais, social e historicamente convencionalizados, que fazem parte da memória cultural de uma comunidade.

Oesterreicher (1997) é um dos autores que se debruçaram sobre esse modelo de análise e explica que os textos, em seus meios e concepções fônicos e escritos, apresentam um continuum de variações, tendo, então, as TDs "um caráter móvel”. O mesmo autor (1997) sugere que as TDs constituem, juntamente com a língua, um filtro que leva à finalidade comunicativa, ou seja, à finalidade do enunciado. Sobre essa consideração de Oesterreicher, Kabatek (2003) afirma que, desse modo, as TDs "compartilham a mesma historicidade do que as línguas". Em outras palavras, consistem em historicidades diferentes, porém complementares.

Costa (2012, p. 148) afirma que "o lugar das tradições discursivas na teoria linguística está inevitavelmente ligado ao próprio conceito de texto". Assim sendo, compreendemos que todo texto é um tipo de ação linguística, que se concretiza em um gênero, e as TDs abrangem distintos graus de abstração e complexidade de modelos textuais, ou seja, das dimensões mais pontuais como uma saudação (Bom dia) às dimensões mais amplas como uma carta de amigo. Segundo Koch $(1998$, p. 14) todo discurso está situado em determinadas tradições históricas:

De um lado, na tradição de uma dada língua particular (ou variedade linguística), de outro, em determinada tradição discursiva. Esse último termo diz que todo discurso é exemplar de algum gênero literário, gênero textual ou forma conversacional, apresenta traços de uma determinada 
orientação estilística, serve para execução de atos de fala marcados historicamente etc.

Desse modo, os gêneros estão intrinsecamente articulados com as práticas sociais, aspectos cognitivos, interesses, relações de poder, tecnologias, atividades discursivas e culturais. Marcuschi (2011, p. 19) diz que "eles (os gêneros) mudam, fundem-se, misturam-se para manter sua identidade funcional com inovação organizacional”. Nesse sentido, além de ser uma rica fonte aos estudos da história das línguas, as cartas pessoais constituem um exemplo eficaz da relação existente entre tradições existentes e inovação no contexto sócio-histórico, e essa dinâmica não pode ficar à margem das discussões na sala de aula.

\section{O hipergênero carta e o subgênero carta de amigo}

A respeito da abordagem dos gêneros, Bakhtin (2000) considera que esses "tipos relativamente estáveis de enunciados" auxiliam o desenvolvimento dos diferentes processos de comunicação. Faraco (2003 p. 112), sobre essa máxima bakhtiniana, afirma que o pensador russo “está dando relevo, de um lado, à historicidade dos gêneros; e, de outro, à necessária imprecisão de suas características e fronteiras”. Outros autores revisitaram as teorias bakhtinianas, tanto para reavaliar seus conceitos, como para confirmar suas ideias.

Dentre os autores que revisitaram a teoria de Bakhtin, podemos destacar Maingueneau (2006), que argumenta que os rótulos podem exercer influência sobre os aspectos formais e de interpretação dos gêneros. Segundo ele, o uso dos rótulos é o que caracteriza os hipergêneros, exemplificando que a correspondência epistolar, por sua proximidade com o intercâmbio conversacional, permite formatar os mais diferentes conteúdos sob o mesmo rótulo (op. cit., p. 244)

Baseamo-nos, portanto, na concepção de hipergênero como um conceito mais geral, a exemplo da carta que agrupa vários rótulos; o termo gênero é, então, tomado aqui para designar a carta pessoal, que abriga, de acordo com Souza (2012), três subgêneros fundamentais: cartas de família (correspondências produzidas entre membros da família nuclear), cartas de amor (trocadas entre cônjuges, pretendentes, noivos etc.) e cartas 
de amigo (trocadas entre amigos/colegas com maior ou menor nível de intimidade e parentes), que aqui serão analisadas.

Apoiamo-nos no pressuposto de que as classificações de um gênero são necessárias dentro do seu processo de análise, "entretanto não são definitivas e nem correspondem ao fim de uma abordagem" (GOMES, 2007, p. 106). Sob essa perspectiva, reconhecemos as cartas pessoais como um rótulo que agrupa outros subgêneros, numa variedade de formas de interação social. A caracterização das cartas como hipergênero se baseia no fato de que delas emergem, se ramificam e se multiplicam os diversos gêneros discursivos, como cartas de redator, cartas comerciais, cartas administrativas, cartas pessoais etc., "os quais exercem a sua função de acordo com as características de cada um e sua finalidade de intermediar a comunicação entre os usuários" (MELO; BRITO, 2010, p. 4).

Esse movimento de transformação e de autonomia dos gêneros vai formando o acervo textual, que Koch (1997, p. 14-16) pontua como filtros que pertencem à (i) inovação por diferenciação de tradições culturais; (ii) inovação por mistura de tradições culturais; e (iii) inovação por convergência de tradições culturais.

No que diz respeito aos traços característicos da carta pessoal, geralmente é uma tradição comunicativa carregada de subjetividade e que traduz a expressão pessoal do emissor. Este tipo de correspondência é especificamente utilizado na comunicação entre sujeitos que mantêm um vínculo de relacionamento; sua finalidade discursiva pode transitar por objetivos diversos - fazer um convite, prestar agradecimentos, relatar algum fato ocorrido, solicitar informações etc.

Dentre os elementos constitutivos das missivas, há alguns que "parecem essenciais e necessários a todos os gêneros provenientes da carta que circulam nas diferentes instâncias e domínios discursivos, decorrentes do caráter formulaico do gênero" (NASCIMENTO; ESPÍNDOLA, 2008 , p. 4). Os mesmos autores acrescentam que os gêneros formulaicos "são aqueles vistos como exemplares que seguem um padrão formal de construção, como é o exemplo da carta, da ata de reuniões, do parecer, etc.”. Silva (2007, p. 24) argumenta que "nos gêneros formulaicos, padronizados, haverá um direcionamento, instruído pela intenção do locutor, para o qual deve convergir a percepção do outro". 
Sob essa perspectiva, é importante elencar os componentes constitutivos da carta, que são comuns ao subgênero aqui tratado: a especificação do local e da data, o vocativo, a captação de benevolência, o corpo do texto e a despedida. O local e a data fazem parte dos traços mais fixos da missiva, bem como o vocativo, que marca textualmente o interlocutor; a captação de benevolência pode aparecer na totalidade da carta ou em partes específicas, como a saudação ou conclusão; no corpo ou núcleo da carta, encontramos o motivo pelo qual a missiva está sendo escrita; a despedida geralmente é elaborada numa constituição formulaica, recorrente, conectada com a natureza do gênero e conta com a identificação, a assinatura do missivista.

Sobre o tratamento das cartas pelo viés escolar, consoante Santos e Silva (2014), a escola é responsável pela sistematização do ensino de gêneros textuais, sem rejeitar os gêneros previamente aprendidos pelos alunos. Nesse sentido, devido à complexidade dos elementos relacionados ao ensino da escrita, é importante salientar que fala e escrita se complementam e que isso pode ser notado nas cartas, que podem oscilar entre proximidade e distância de uma conversa face a face. Segundo Soto (2001, p. 23):

São muitos os benefícios que este gênero oferece. "A carta apresenta a vantagem adicional de ser um texto que é pensado como um diálogo que acontece a distância e por isso tem como características imanentes ser escrito e se realizar sem a presença dos interlocutores”.

Notamos, portanto, que as cartas propiciam aos alunos uma imersão nas práticas sociais, como veremos mais adiante. Antes de partirmos para a análise da composição das cartas de amigo, é importante conhecer o perfil sócio-histórico dos escreventes e destinatários dessas cartas.

\section{Perfil dos escreventes e destinatários}

As correspondências coletadas foram produzidas entres os anos de 1903 e 1940 e apresentam características semelhantes: cartas pessoais produzidas por pernambucanos (dentro ou fora do estado de Pernambuco) na primeira metade do século XX. Boa parte das missivas analisadas foi coletada na Fundação Joaquim Nabuco, em Recife. Essa parte das missivas 
corresponde aos escreventes ilustres, com alto nível de letramento e : escolaridade, mas há também correspondências escritas por seus familiares, : também ilustres ou não.

Por meio do local, da data e do vocativo das cartas, é possível identificar informações essenciais acerca da natureza dos subgêneros da carta pessoal. Através das missivas "passamos a conhecer o entorno de quem as escreveu, sobre o local onde vivia, quando escreveu, além obviamente de podermos identificar as estratégias linguísticas utilizadas" (LOPES e GOMES, 2016, p. 5). As estratégias linguísticas empregadas expõem as variações linguísticas consoantes ao momento histórico, ao local, e ao perfil socioeconômico dos interlocutores, como também revelam atos linguísticos recorrentes e tradicionais, próprios da natureza do gênero, e não necessariamente da norma linguística vigente. Esses atos linguísticos recorrentes são tradições discursivas que constituem a tradição missivista, cujos escreventes e destinatários são os seguintes:

- Breno Braga (carta 1 - 1941) - major do Exército Brasileiro.

- Carlos Alberto de Menezes (Carta 2 - 1904) - engenheiro civil e renomado líder católico.

- Arnaldo Guedes Pereira (Carta 3 - 1922 e Carta 4 - 1930) - não foram encontradas informações sobre seu perfil social, nem dos autores que escreveram para ele.

- Gilberto Freyre (Carta 5 - 1939 e Carta 8 - 1940) - sociólogo e escritor pernambucano. Todas as correspondências de seu acervo são passivas e foram escritas por Jarbas Pernambucano de Melo (filho de Ulisses Pernambucano e primo de Gilberto Freyre) e José Antônio Gonsalves de Mello Neto (grande historiador brasileiro).

- Joaquim Nabuco (Carta 6 - 1904 e Carta 7 - 1903) - brasileiro político, diplomata, historiador, jurista, jornalista, formado pela Faculdade de Direito de São Paulo. Foi um dos fundadores da Academia Brasileira de Letras.

Mesmo com algumas informações incompletas, foi possível recuperar o perfil da maioria dos escreventes, sobretudo os distanciados pelo tempo. Sem dúvida, é fundamental o conhecimento do perfil social dos missivistas, uma vez que tais dados contribuem para a análise dos 
: elementos composicionais, dos recursos linguístico-discursivos empregados

: nas cartas e das tradições discursivas que compõem as missivas. Neste corpus, as cartas são trocadas entre amigos e primos, vejamos o que elas revelam.

\section{As Cartas de amigo}

O rótulo "carta de amigo" agrupa correspondências entre membros da família ampliada, pessoas com algum grau de conhecimento (com distintos níveis de proximidade) etc. (SOUZA, 2012). Os escreventes dos subgêneros analisados são pessoas ilustres, com alto nível de escolaridade, como Joaquim Nabuco e Jarbas Pernambucano de Melo. Dentre os destinatários, encontram-se pessoas também ilustres e cultas, como Gilberto Freyre e Carlos Alberto de Menezes.

A análise do corpus pautou-se em três categorias básicas de observação: os elementos composicionais, os elementos linguístico-discursivos e as tradições discursivas. Buscamos identificar nos textos os modos de dizer, ou seja, as estratégias linguístico-discursivas recorrentes, que podem se configurar, ou não, como TD e as estratégias que indicam o tipo de vínculo estabelecido entre os interlocutores. Dentre essas estratégias, investigaremos as formas de tratamento empregadas, de acordo com as relações estabelecidas entre os interlocutores.

Os temas das cartas são bastante diversos. Os missivistas escrevem para dar notícias de viagem (Carta 1), relatar falta de tempo para atividades sociais (Carta 3), prestar condolências pela morte do filho do destinatário (Carta 4), dar e pedir notícias (Carta 5), apresentar um amigo para fins comerciais (Carta 6), parabenizar o destinatário por um poema publicado (Carta 7) e pedir informações acadêmicas (Carta 8). As relações entre os remetentes e os destinatários das correspondências apresentam certa proximidade, hora familiar (Gilberto Freyre e seu primo Jarbas Pernambucano), hora de amizade (Joaquim Nabuco e seu amigo Galvão). Há também cartas que fogem, um pouco, dos protótipos de carta de amigo, como é o caso da Carta 2, na qual o remetente pede ajuda para uma situação empregatícia, e das cartas 3 e 4, escritas em verso. Algumas das correspondências podem se assemelhar mais a uma carta comercial, mas o grau de intimidade entre os interlocutores se estabelece, 
no texto, simetricamente, existindo uma relação de solidariedade entre os participantes da situação comunicativa (LOPES E GOMES, 2016).

De acordo com Lopes (2011, p. 368), devido à temática íntima e/ ou espontânea, "a carta pessoal pode facilitar na identificação de fatos linguísticos em processos de mudança”. A mesma pesquisadora ainda afirma que se, por um lado, a carta veicula a inovação e mudança linguística, por outro, preserva fórmulas fixas em que se perpetuam "tipos estáveis de enunciados”, caracterizando-a como gênero discursivo (SOTO, 2001).

No que diz respeito aos elementos composicionais das cartas, sejam fórmulas fixas ou não, percebemos que a relação de solidariedade entre remetentes e destinatários começa a ser estabelecida a partir do vocativo, elemento que, juntamente com a captação de benevolência, no início do texto, revela a "afetividade e a proximidade respeitosa estabelecida entre os dois interlocutores” (LOPES E GOMES, 2016, p. 7). Em relação ao vocativo, são detectadas, no corpus, as ocorrências do nome do destinatário e de algum elemento de qualificação, indicador da relação estabelecida (Meu caro Dr. Velloso (Carta 1); Amigo Doutor Carlos Alberto (Carta 2); Arnaldo, meu grande amigo (Carta 3); Meu caro Arnaldo (Carta 4); Caro Gilberto (Carta 5); Meu caro Paranhos (Carta 6); Meu caro Colega Dr. Galvão (Carta 7); Mestre amigo (Carta 8). Juntamente com o indicativo de data e local, a saudação já dá indícios, como podemos perceber, do tipo de relação que o interlocutor pretende firmar (LOPES, 2011), consolidando a amizade como fundamento para um pedido de informações, notícias ou favores. Na composição do vocativo, a recorrência do pronome possessivo de primeira pessoa "meu", juntamente com adjetivos como "caro" e "grande", além da explicitude do termo "amigo" configuram-se como um modo de dizer tradicional e recorrente na abertura das cartas de amigo.

Em relação à captação de benevolência, notamos que esta forma fixa típica do gênero carta faz parte do contato inicial mantido com o interlocutor. Em algumas missivas analisadas pertencentes ao subgênero carta de amigo, a captação de benevolência foi dispensada, devido, provavelmente, à formalidade que permeia algumas relações de amizade que mantêm certo distanciamento. Nessas cartas as relações nem sempre são guiadas pela afetividade, estando, de tal maneira, em situação de 
interação com uma diversidade de destinatários, muitos deles cultos

: (colegas de profissão ou pessoas que ocupam postos sociais elevados). Nesses casos, verificamos que as estratégias mais utilizadas foram a confirmação do recebimento de correspondências anteriores (Cartas 4, 7 e 8) ou justificativa pela demora a escrever (Carta 3), em substituição à captação de benevolência. $\mathrm{Na}$ Carta 2, o missivista abre mão de saudações e já inicia o assunto, passando do vocativo para o corpo do texto:

(Ex. 1) Meu caro Paranhos,

Quero ter o prazer de apresentar-lhe| <o meu>2 amigo[]3 dezembargador | Domingos Alves Ribeiro. É um dos meus | mais íntimos amigos, e devo essa amizade | ao Dantas, e tambem, indireta- $\mid$ mente, ao José Bonifacio. (Carta 2)

A Carta 2, por ser bem mais objetiva (porque se trata de um pedido), não apresenta captação de benevolência. Os escreventes das cartas 5 e 8, por apresentarem um grau de intimidade mais elevado com os destinatários (primos), estabelecem uma relação pautada na afetividade registrada na captação de benevolência no início do texto:

(Ex. 2) Um abraço você como você como vai passando | nós aqui vamos tudo bem. (Carta 5)

(Ex. 3) Um abraço. Recebi ha dias a sua | carta. (Carta 8)

Percebemos que os escreventes das cartas 5 e 8 utilizaram uma TD recorrente nas despedidas das cartas, porém a empregaram no início dos respectivos textos. Nos exemplos citados, a TD "Um abraço" introduz o ato comunicativo, faz parte da abertura do texto, com função pragmática de captar a benevolência do interlocutor, porém, quando situada no final da carta, encerra a comunicação, exercendo a função pragmática de uma despedida. De tal maneira, identificamos essa TD aqui utilizada não apenas como um simples enunciado, mas como uma ação linguística que relaciona o texto com uma situação real, e que também relaciona esse mesmo texto com outros da mesma tradição (KABATEK, 2006), no caso, com as outras cartas que compartilham da mesma TD de abertura e de fechamento. 
Sendo assim, percebemos, nesse bloco de tradições discursivas situadas na abertura das missivas, identificadas de acordo com as palavras, expressões e saudações empregadas, as diferentes relações, de acordo com o nível de proximidade entre os interlocutores. $\mathrm{O}$ modo de dizer recorrente nas cartas de amigo "um abraço" denota afetividade e se configura como uma TD que possibilita a repetição de uma estratégia discursiva, tanto na abertura quanto no fechamento do texto, criando um elemento composicional recorrente na moldura deste subgênero. Essa escolha de palavras muito diz respeito ao objetivo da correspondência: se a intenção é ser mais direto, se há um objetivo específico urgente, se é apenas uma troca de notícias corriqueiras etc. Ao longo da tradição epistolar, sempre houve a preocupação em outorgar respeito aos papéis sociais do emissor e do receptor na seção de contato inicial e saudação (BAZERMAN, 2005, p.9).

Tais elementos se configuram como TD nas cartas de amigo mediante a repetição desses traços, que se tornaram historicamente caracterizadores do subgênero, considerando as condições de produção dos textos. Verificamos, portanto, que a presença dessas TDs nas cartas auxilia a constituição do estilo do subgênero. Em síntese, segundo Longhin (2014, p. 37), as distintas escolhas linguísticas refletem, em sua maioria, diferenças nos propósitos comunicativos e em outras condições de produção dos textos. Por essa razão, algumas ocorrências linguísticas são próprias da natureza do gênero historicamente dada, e não necessariamente da norma de uso vigente.

Passando para o interior da carta, conforme os estudos de Lopes (2011, p. 370), o corpo da carta é uma fração mais flexível em termos estruturais e temáticos. No núcleo, encontra-se "a razão pela qual se está escrevendo a carta". O tema é um dos itens que apresentam maior fluidez na composição da carta, ou seja, os temas aparecem naturalmente, gerados pelo discurso prévio (BERENGUER, 1994). Desse modo, mantêm-se a forma, mas diversificam-se os temas. A pluralidade temática, juntamente com a espontaneidade são alguns dos fatores que compõem as condições comunicativas das tradições discursivas (OESTERREICHER, 2006, apud LONGHIN, 2014).

Também nas cartas pessoais é possível verificar a estabilidade relativa das formas textuais. As cartas 3 e 4, por exemplo, fogem do 
protótipo formal das missivas particulares de amigos. Elas são escritas : em verso (provavelmente pelo mesmo autor, que teria assinado com nomes distintos), mas não abrem mão dos demais traços composicionais e tradições discursivas pertencentes ao subgênero. Ocorre, nessas cartas, o fenômeno denominado intergenericidade (KOCH e ELIAS, 2007, p. $114)^{3}$. As autoras afirmam que "um gênero pode assumir a forma de outro gênero, tendo em vista o propósito de comunicação”. Podemos perceber, no corpo das duas cartas, que as finalidades comunicativas e as relações estabelecidas estão delimitadas e que a função comunicativa da carta foi mantida:

(Ex. 4) Embora tendo sciencia, | Que tinhas intelligencia | é regular instrucção, | Eu ainda não sabia, | Que davas p'ra poesia, | Com tamanha perfeição. || No principio deste anno, | Na fazenda do teu mano, | com os teus me misturei; | Eu fui tão bem acolhido, | Que até fiquei comovido! | Jamais eu me esquecerei..... || Pesquei, caçei, cavalguei, | Muitos moveis carreguei, | Fui copeiro dedicado, | Tive meu nome na imprensa, | Dei um baque na dispensa, | Mas voltei gordo e corado. | | [fol. 2 v] Eu tenho ahi um amigo, | Que sem receio eu te digo, | Seja embora teu parente, | Por ter no peito uma rosa, | Ficou ancho, ficou prosa, | Até se esqueceu dagente. (Carta 3)

(Ex. 5) Ver um filho a dormir na ardente-sala

O somno eterno, ao coração sensível

Dos Paes é sobrehumano. Assim nos fala

A razão que com a dor é compativel.

Ao proprio coração, entanto, a calma

Retorna em breve, em face da certeza

De que não soffrerá jamais essa alma. (Carta 4)

De modo geral, as missivas analisadas apresentam núcleos com construções objetivas, nas quais se tornam nítidos os objetivos do escrevente, a intenção da ação comunicativa e as respostas esperadas dos

$3 \mathrm{Um}$ estudo detalhado sobre a intergenericidade encontra-se no artigo publicado por CAVALCANTI, Carolina e GOMES, Valéria. O editorial no jornal O Carapuceiro e a transposição para o ensino. Revista Encontros de Vista, Edição JAN / JUN - 2013. Consultado em 10 de Junho de 2015. 
destinatários. Os excertos a seguir demostram essa objetividade:

(Ex. 6) Amanhã devo chegar ahí ás 9.10 na estação da Baltimore and | Ohio R.R. Queria avisar o Mengoli e fazer guardar-me no hotel o| mesmo aposento que tive. | | Faça me o favor de suspender a remessa de correspondencial para New York e de fazer retirar esses registados do Correio del modo que eu já os encontre no hotel. O Perdeneiras e o Chermant | me acompanham, vão sem a familia, como eu. (Carta 1)

(Ex. 7) "Quero ter o prazer de apresentar-lhe | <o meu>2 amigo[]3 dezembargador| Domingos Alves Ribeiro. É um dos meus | mais íntimos amigos, e devo essa amizade|[]4 ao Dantas, e tambem, indireta-| mente, ao José Bonifacio.” (Carta 7)

(Ex. 8) "Veja se há | meio de arranjar colaboração aí para | nossa revista. || $\mathrm{Na}$ sua casa vão todos bem. | outra coisa que papai lhe pede é que | você , caso não seja incômodo, saber se algum | laboratório americano de medicamentos se | interesse em nos vender ácido nicotínico | em substância.” (Carta 5)

As partes finais da carta, seção de despedida e assinatura, são estruturas mais estáveis e podem conter também trechos de captação da benevolência. A seção de despedida das cartas agrupa, pelo menos, duas tradições discursivas: o emprego de orações imperativas, no campo linguístico, e as recomendações, no campo discursivo. Percebemos, nessa seção, uma grande quantidade de expressões que denotam afetividade e solidariedade, como se pode constatar a seguir:

(Ex. 9) Até amanhã. || Do seu affm $^{\circ}($ Carta 1$)$

(Ex. 10) "Espero suas ordens, caru a-| migo certo" (Carta 2)

(Ex. 11) "Um beijo muito apertado | E um grande abraço na testa." (Carta 3)

(Ex. 12) "Um abraço emotivo para todos os teus. Para a tua querida | pessôa, a alma entristecida mas sempre amiga do teu [inint.] corde” (Carta 4)

(Ex. 13) "Para você meus abraços nossos e | agradecimentos." (Carta 5)

(Ex. 14) "O resto [init.] | me dirão algum dia.>10 || Do seu sempre dedicado" (Carta 6) 
(Ex. 14) "Creia-me seu Patricio e amigo" (Carta 7)

(Ex. 15) "Lembranças para as tias e você receba | um abraço do primo e amigo de sempre.” (Carta 8)

Foi possível observar, na seção de despedida, a presença de construções frasais com verbos no imperativo em três das cartas de amigo. De acordo com Silva (2013), nas cartas pessoais, o imperativo, historicamente, passou a perder seu sentido mais básico, relacionado à ordem, tomando, então, sentidos que fazem alusão à função pragmática de um pedido, uma solicitação, uma exortação, uma recomendação, um desejo etc. Silva (2013, p. 18) comenta que:

Assim, o imperativo poderia ser entendido como uma construção que originalmente denotava ordem e, com a extensão de significado e a ampliação do seu uso mediante a criatividade do falante se expandiu e passou a atuar em novos contextos.

Devido ao fato de os interlocutores possuírem certo grau de intimidade, pretendem estabelecer ou afirmar a amizade através dos modos de dizer. Apesar da objetividade notada como típica ao subgênero carta de amigo, os escreventes das cartas 2, 3, 4, 5, 6, 7 e 8 utilizaram estratégias que revelam proximidade comunicativa, guiada pelo nível de intimidade. Boa parte dessas relações foi estabelecida nas supracitadas seções de abertura e fechamento das missivas, que deixam transparecer "o grau de emocionalidade, que inclui a emocionalidade dirigida a parceiros da comunicação (afetividade) ou a objetos (expressividade)" (COSTA, 2012, p. 159).

Considerando a dinamicidade e a convencionalidade inscritas nas práticas do gênero carta pessoal (SILVA, 2002), verificamos também a questão do sujeito linguisticamente marcado nos textos em questão. Souza (2012, p. 91) argumenta que a referência ao remetente pode ser feita de várias formas e chama atenção para as formas de tratamento pronominais na segunda pessoa ( $t u$ e você). A mesma autora comenta que a forma tu passou a ser suplantada pelo pronome você a partir da década de 1930. Portanto, o momento histórico em que as cartas estão inseridas faz parte de um período de transição das formas de tratamento empregadas no Rio 
de Janeiro, local onde foram coletadas as cartas analisadas por Souza. A proximidade comunicativa percebida nas cartas pessoais faz com que esse gênero dê um testemunho preliminar e panorâmico dessa transição das formas de tratamento também no contexto de Pernambuco, uma vez que essa mistura de tratamentos já tem registro em anos anteriores à primeira metade do século $\mathrm{XX}^{4}$.

Nas cartas de amigo analisadas, é maior a ocorrência da forma de tratamento marcada pelo pronome você, a exemplo das cartas de Joaquim Nabuco, que datam do início do século XX (1903 - 1905). Apenas duas cartas de amigo (castas 3 e 4) apresentam o pronome tu como forma de tratamento. Isso se deve, provavelmente, a grau de proximidade entre os interlocutores e ao fato de as cartas serem escritas em verso, o que leva o escrevente a buscar uma padronização na forma de tratamento adotada do início ao fim. De acordo com Lopes e Gomes (2016, p. 11), a forma você apresentava, nessa época, um comportamento híbrido, podendo representar mais intimidade (como no tratamento dos primos Jarbas Pernambucano de Melo e Gilberto Freyre) ou mais formalidade (como na relação de negócios entre Paranhos e Joaquim Nabuco).

Em síntese, é possível perceber, nesse subgrupo, a ocorrência de tradições discursivas e formas cristalizadas oriundas da tradição epistolar, principalmente no início e no fim das cartas. Com base na finalidade comunicativa, nos temas abordados e nas relações estabelecidas entre as pessoas do discurso, é possível identificar traços específicos do subgênero carta de amigo, que notoriamente o difere dos subgêneros carta de família e de amor, o que evidencia as especificidades na composição do gênero carta pessoal. Nas cartas de amigo, tornaram-se notórias as finalidades comunicativas, que juntamente com as condições de produção determinam o que e como dizer, produzindo, então, sentido (LONGHIN, 2014).

\section{As cartas de amigo: reflexões para o ensino}

Na perspectiva de Marcuschi (2000, apud SILVA, 2002), a sociedade elabora e atualiza gêneros textuais para atender as necessidades comunicativas das pessoas. Nesse sentido, toda abordagem de gêneros

4 Estudos voltados especificamente para a questão das formas de tratamento em Pernambuco, a exemplo de Lopes e Gomes (2016), apresentam dados mais detalhados. 
textuais no âmbito escolar deve partir de eventos e situações reais, em "espaços sociais em que as pessoas agem, interagem e assumem papéis comunicativos e posições sociais específicas” (SILVA, 2002, p. 30).

Assim como os demais subgêneros da carta pessoal, as cartas de amigo promovem situações de interação entre os sujeitos e suas práticas de leitura e escrita. Como foi anteriormente visto, a missiva trocada entre amigos pode comportar distintos propósitos comunicativos e distintas formas de organização. Assim sendo, uma abordagem eficaz desse subgênero, ancorada no modelo de Tradições Discursivas, como propusemos aqui, especialmente no que diz respeito à diacronia dos textos, ou a um recorte de sincronia passada, deve considerar prioritariamente os fatores sóciohistóricos que permeiam a carta. A abordagem de sincronias passadas ainda é pouco explorada no contexto escolar e pode oferecer, numa perspectiva interdisciplinar, muitos elementos de reflexão, passando pela História da língua e dos textos, verificando os traços linguísticos e composicionais de gêneros de diferentes épocas; percebendo as continuidades e as rupturas nos modos de dizer em gêneros diversos, de acordo com as condições de produção; valorizando o patrimônio cultural por meio do trabalho com corpus histórico, entre muitas outras ideias.

Além da análise dos elementos de organização retórica dos gêneros e subgêneros, o trabalho com as cartas de amigo propicia abordagens que visam à Análise Linguística. Silva e Santos (2014, p. 18) apontam que as cartas pessoais proporcionam um interessante enfoque em ortografia, uso do vocativo e dos pronomes, linguagem formal/informal; os modos de dizer tradicionais da estrutura das cartas, em consonância com a função social do gênero. A variação das formas pronominais "tu" e "você", por exemplo, pode ser trabalhado com base em correspondências pessoais, de ilustres ou não, considerando as relações de simetria e assimetria entre os interlocutores, os contextos de variação entre "tu" e "você" em uma mesma correspondência, os fatores que condicionam essa ocorrência, os subgêneros que propiciam mais o emprego de uma forma pronominal ou de outra, etc. Em todo esse processo, podemos considerar quais são as marcas de interação mais frequentemente usadas nas construções das cartas e sob que contextos tais marcas emergem, levando à reflexão sobre o caráter de "conversação escrita” da carta pessoal (GOMES; LOPES, 2016, p. 5). 
Ademais, com o surgimento e o aperfeiçoamento de formas de comunicação mais ágeis, é possível que os próprios alunos percebam as : semelhanças existentes entre as cartas de amigo (e as demais cartas pessoais) e esses novos meios de comunicação, uma vez que todos esses instrumentos comunicacionais objetivam "aproximar pessoas distantes por meio da escrita” (SILVA; SANTOS, 2014, p. 18). A nosso ver, tornar acessíveis textos de sincronias passadas poderia motivar os alunos a entenderem que somos todos nós os agentes da História social, cultural, da Língua e dos Textos.

\section{CONSIDERAÇÕES FINAIS}

De modo geral, as correspondências pessoais revelam relações de proximidade entre os interlocutores. Tais relações são manifestadas por meio dos recursos linguístico-discursivos utilizados para esse fim. O agenciamento dos recursos linguísticos - "seleção de tratamento, estruturação sintática -, a disposição temática, a escolha de estratégias de polidez ou interativas traduzem a singularidade e a individualidade do escrevente" (SILVA, 2002, p. 157), além de evidenciar a relação estabelecida, conforme o subgênero carta de amigo evidencia.

Nessas cartas, observamos que os fatores formais, a abertura, a captação da benevolência, o corpo da carta e o fechamento, apresentam-se de modo recorrente, configurando-se como Tradições Discursivas (TD). Os vocativos e as despedidas deixam claros traços recorrentes desse subgênero. Percebemos também que as formas de tratamento (no caso, o paradigma do você) podem tanto estar relacionadas com um tratamento respeitoso, como podem caracterizar um contato mais íntimo, devido ao hibridismo do você e a relação estabelecida entre os interlocutores.

No que diz respeito às reflexões para o ensino, por corresponder a uma atividade discursiva real, esse tipo de correspondência pode - e deve - ser levado à sala de aula, a fim de motivar o estudante a identificar a historicidade dos gêneros e da língua, como uma das proposições de ensino voltadas para o desenvolvimento da competência comunicativa e para a ação, a reflexão e o exercício de cidadania, conforme as orientações dos PCNs. 
Acreditamos, portanto, que a caracterização da carta de amigo, entre : os subgêneros da carta pessoal auxilia, também, o estudo de textos escritos na atualidade. Com o advento dos gêneros digitais e de novas formas de comunicação, surge a questão: o que foi mantido e que mudou em relação às tradições discursivas passadas? Consideramos, para isso, que os gêneros passam por processos de adaptação (PESSOA, 2002) que os modificam e originam outros gêneros que correspondem aos mesmos propósitos comunicativos ou a novos propósitos. Nessa dualidade entre a historicidade da língua e do texto, a abordagem pelo viés da Tradição Discursiva ainda é pouco explorada, esperamos que investigações vindouras sejam motivadas pelos passos aqui dados. Limitamo-nos, neste artigo, ao enfoque de alguns fatores composicionais, linguístico-discursivos e as Tradições Discursivas (TD) que constituem a carta de amigo. Nesse sentido, muito ainda há por fazer nessa contínua e prazerosa reflexão sobre as múltiplas formas de uso da linguagem e de interação, seja em sincronia presente ou passada.

\section{REFERÊNCIAS BIBLIOGRÁFICAS}

BAKHTIN, Mikhail. Os gêneros do discurso. In: Estética da criação verbal. Trad. Maria Ermantina Galvão G. Pereira. 3 ed. São Paulo: Martins Fontes, 2000. p. 277-326.

BAZERMAN, C. Gêneros textuais, Tỉificação e interação. São Paulo: Cortez, 2005.

BELTRÁN ALMERÍA, Luís. Las estéticas de los géneros epistolares. Anuario de la Sociedad Española de Literatura General y Comparada, Vol. X (Año 1996), pp. 239-246.

BERENGUER, Josefa Antonia. Estrategias del discurso conversacional: algunos casos de relato coloquial em catalán y español. Universidad Nacional de San Juan: San Juan, 1994.

BEZERRA, M. A.; REINALDO, M. A. Análise linguística: afinal a que se refere? São Paulo: Cortez, 2013. 
BRASIL. Parâmetros curriculares nacionais: terceiro e quarto ciclos do ensino fundamental: introdução. Brasília: MEC/SEF, 1998.

BROWN, R.; GILMAN, A. The pronouns of power and solidarity. In: SEBEOK, T. A. Style in Language. Massachusetts: Ed. MIT Press, 1960, p. 253-276.

CAVALCANTI, Carolina; GOMES, Valéria. O editorial no jornal O Carapuceiro e a transposição para o ensino. Revista Encontros de Vista, Edição JAN / JUN 2013. Consultado em 10 de Junho de 2015.

CONDE SILVESTRE, J. C. Sociolinguistica histórica. Madrid: Gredos, 2007.

COSERIU, Eugênio. Teoria da linguagem e Linguística geral. Trad. Agostinho Dias Carneiro. Rio de Janeiro: Presença Edições, 1979.

COSTA, Alessandra Castilho da. Ação - formulação - tradição: a correspondência de Câmara Cascudo a Mário de Andrade de 1924 a 1944 entre proximidade e distância comunicativa. In: MARTINS, Marco Antonio; TAVARES, Maria Alice. Projeto História do Português Brasileiro no Rio Grande do Norte: análise linguística e textual da correspondência de Luís da Câmara Cascudo e Mário de Andrade - 1924 a 1944. Natal: EDUFRN, 2012.

FARACO, Carlos Alberto. Linguagem \& diálogo: as ideias linguísticas do Círculo de Bakhtin. Curitiba: Criar Edições, 2003.

GOMES, Valéria S. Traços de mudança e de permanência em Editoriais de Jornais pernambucanos da forma ao sentido. Tese de Doutorado apresentada à Universidade Federal de Pernambuco, Recife, 2007.

GOMES, Valéria S.; LOPES, Célia R. dos Santos. Formas tratamentais em cartas escritas em Pernambuco (1869-1969): tradição discursiva e sociopragmática. Revista de Estudos da Linguagem, v. 24, p. 137, 2016.

GUEDES, M. \& BERLINK, R. de A. (ed.). E os preģos eram commodos Anúncios de jornais brasileiros século XIX. São Paulo: Humanitas, 2000. 
: GUILLÉN, Claudio. Al borde de la literariedad : literatura y epistolaridad. : Tropelías, 1991.

KABATEK, J. Tradiciones Discursivas y Cambio Lingüistico. Fundación Duques de Soria. Seminário de História da Língua Espanhola "El cambio lingüístico na historia española. Nuevas perspectivas”. Soria, Del 7 a 11 de Julio de 2003.

. Tradições discursivas e mudança linguística. In: Lobo, T; Ribeiro, I.; Carneiro, Z.; Almeida, N. (Orgs.) Para a história do português brasileiro. Salvador, EDUFBA, tomo II, 2006.

KOCH, Ingedore Villaça; ELIAS, Vanda Maria. Ler e compreender: os sentidos do texto. São Paulo: Contexto, 2007.

KOCH, Peter. Diskurstraditionen:zu ihrem sprachtheoretischen Status und ihrer Dynamik". In: Barbara Frank/Thomas Haye/Doris Tophinke (Hrsg.), Gattungen mittelalterlicher Schriftlichkeit, Tübingen: Narr 1997 (ScriptOralia, 99), 1997, 43-79. (Tradução da Professora Doutora Alessandra Castilho da Costa - UFRN)

- Urkunde, Brief und öffentliche Rede. Eine diskurstraditionelle Filiation im Medienwechsel, Das Mittelalter 3, 1998, 13-44.

KOCH, P.; OESTERREICHER, W. Oralidade y escrituralidad a luz de la Teoria del Lenguage. In: ___. Lengua Hablada en La Romania: español, francés, italiano. Madrid; Editorial Gredos, 2007, pp. 20-42.

LONGHIN, Sanderléia Roberta. Tradições discursivas: conceito, história e aquisição. São Paulo, 2014.

LOPES, C. R. dos S. Tradição Discursiva e Mudança no Sistema de Tratamento:

definindo perfis comportamentais no início do século XX em cartas do RJ. Revista Alfa, São Paulo, 55 (2): 361-392, 2011.

MAINGUENEAU, Dominique. Discurso Literário. Trad. Adail Sobral. São Paulo: Contexto, 2006. 
MARCUSCHI, L. A. Gêneros textuais: configuração, dinamicidade e circulação. In: KARWOSKI, A. M.; GAYDECZKA, B.; BRITO, K. S. (Orgs.). Gêneros Textuais: reflexões e ensino. 4. ed. São Paulo: Parábola Editorial, 2011. p. 17-31.

MELO, N. M. F. S.; BRITO, E. M. O Ambiente Virtual de Aprendiragem Moodle como espaço formativo de múltiplas linguagens - particularidades de um hipergênero.In: II Seminário de Estudos de Linguagem e Educação, 2011, Vitória da Conquista. Anais do II Seled - Seminário de estudos em linguagem e educação. Vitória da Conquista, 2011. p. 111-125.

NASCIMENTO, Erivaldo P. do; ESPÍNDOLA, Lucienne. Marcas do interlocutor em cartas produzidas na questão de redação do PSS 2008 da UFPB. Revista do GELNE (UFC) , v. 8, p. 133-146, 2008. Acesso em 09/05/2015.

NOVAES, Ana Maria Pires. Carta: uma leitura bakbtiniana do gênero. In: X Congresso Internacional da Associação Brasileira de Literatura Comparada, 2006, Rio de Janeiro. Lugares dos Discursos. Rio de Janeiro: ABRALIC, 2006.

OESTERREICHER, WULF (1997): Zur Fundierung von Diskurstraditionen, en: Frank et al. (1997), 19-41.

PESSOA, Marlos de Barros. Da carta a outros gêneros textuais. In: LAMOGLIA, Maria Eugênia \& CALLOU, Dinah et. al. (Orgs.). Para a história do Português brasileiro. Notícias de corpora e outros estudos - vol. IV. Rio de Janeiro: UFRJ/FAPERJ, 2002, 197-205.

RAMOS, Paulo. Histórias em quadrinhos: gênero ou hipergênero? Revista Estudos Linguísticos - GEL, Edição SET/DEZ - 2009. Consultado em 12/05/2015.

RIZZINI, Carlos. O jornalismo antes da tipografia. São Paulo: Companhia Editora Nacional, 1968.

SCHILIEBEN-LANGE, Brigitte. História do falar e história da lingüistica. Trad. Fernando Tarallo et. al. Campinas: Editora da UNICAMP, 1993.

SANTOS, Erenice B dos; SILVA, Flávio B. Carta Pessoal: uma produção 
textual que sobreviveu ao tempo. Os desafios da escola pública paranaense

: na perspectiva do professor PDE. 2014, volume 1. Disponível em <http://www.diaadiaeducacao.pr.gov.br/portals/cadernospde/pdebusca/ producoes pde/2014/2014 unespar-paranavai port artigo erenice bezerra dos santos.pdf $>$ acesso em 28/12/2016.

SILVA, Érica Nascimento. Uma análise sociofuncionalista do imperativo relacionado ao subjuntivo e indicativo em cartas amorosas de 1930. Revista Semioses, JAN/JUN - 2013. Acesso em 30/05/2015.

SILVA, Érica Nascimento; LOPES, C. R. dos S. O perfil sociolinguístico de um casal não ilustre: uma análise grafemática através da edição de cartas particulares. Revista Confluência. Edição JUL/DEZ - 2012. Consultado em 16/04/2015.

SILVA, Jane Q. G. Um estudo sobre o gênero carta pessoal: das práticas comunicativas aos indícios de interatividade na escrita dos textos. 2002. Tese de Doutorado apresentada à Universidade Federal de Minas Gerais, Belo Horizonte, 2002.

SILVA, Joselí Maria da. A Subjetividade Linguisticamente Marcada em Pareceres Técnicos e Jurídicos. João Pessoa: UFPB, 2007.

SOTO, E. U.M. S. Cartas através do tempo: o lugar do outro na correspondência brasileira. Niterói: Ed. da UFF, 2007.

SOUZA, Camila Duarte de; OLIVEIRA, Thiago L. de. A representação da $2^{a}$ pessoa nas posições de complemento: o papel da categoria social. Work. Pap. Linguíst., 13(2): 100-120, Florianópolis, ABR/JUL, 2013.

SOUZA, Cristiéle Santos de; GASTAUD, Carla Rodrigues. A escrita epistolar de Dom Joaquim e os tratados de epistolografia da Ars Dictaminis: permanências e rupturas. XI Encontro Nacional de História. Universidade Federal do Rio Grande - Rio Grande. 23 a 27 de julho de 2012.

SOUZA, Janaína Pedreira Fernandes de. Mapeando a entrada do você no quadro pronominal: análise de cartas familiares dos séculos XIX-XX. Dissertação de Mestrado apresentada à Universidade Federal do Rio de Janeiro, Rio de Janeiro, 2012. 